\title{
Interannual Agulhas Leakage Variability and Its Regional Climate Imprints
}

\author{
Yu Cheng, Lisa M. Beal, Ben P. Kirtman, and Dian Putrasahan \\ Rosenstiel School of Marine and Atmospheric Sciences, University of Miami, Miami, Florida
}

(Manuscript received 27 September 2017, in final form 10 October 2018)

\begin{abstract}
We investigate the interannual variability of Agulhas leakage in an ocean-eddy-resolving coupled simulation and characterize its influence on regional climate. Many observational leakage estimates are based on the study of Agulhas rings, whereas recent model studies suggest that rings and eddies carry less than half of leakage transport. While leakage variability is dominated by eddies at seasonal time scales, the noneddy leakage transport is likely to be constrained by large-scale forcing at longer time scales. To investigate this, leakage transport is quantified using an offline Lagrangian particle tracking approach. We decompose the velocity field into eddying and large-scale fields and then recreate a number of total velocity fields by modifying the eddying component to assess the dependence of leakage variability on the eddies. We find that the resulting leakage time series show strong coherence at periods longer than 1000 days and that $50 \%$ of the variance at interannual time scales is linked to the smoothed, large-scale field. As shown previously in ocean models, we find Agulhas leakage variability to be related to a meridional shift and/or strengthening of the westerlies. High leakage periods are associated with east-west contrasting patterns of sea surface temperature, surface heat fluxes, and convective rainfall, with positive anomalies over the retroflection region and negative anomalies within the Indian Ocean to the east. High leakage periods are also related to reduced inland convective rainfall over southeastern Africa in austral summer.
\end{abstract}

\section{Introduction}

While the majority of the Agulhas Current turns eastward beyond the tip of the African continent, some of its warm and salty waters leak into the South Atlantic Ocean in the form of eddies and filaments (Gordon 1986; Gordon et al. 1992; Biastoch et al. 2009). The so-called Agulhas leakage and its associated buoyancy fluxes potentially play a role in global climate at broad time scales by modifying the convective stability of the Atlantic meridional overturning circulation (AMOC) (Weijer et al. 2002; Peeters et al. 2004; Biastoch et al. 2008a; Beal et al. 2011; Weijer and van Sebille 2014; Biastoch et al. 2015). Previous leakage studies are mostly based on ocean circulation models (OGCMs) forced by prescribed wind forcing (Backeberg et al. 2008; Biastoch et al. 2009; Rouault et al. 2009; Biastoch and Böning 2013; Biastoch et al. 2015; Loveday et al. 2015; Castellanos et al. 2016). To relate leakage to AMOC and climate variability, coupled models could be complementary to OGCMs, because they include air-sea coupling effects that are important on interannualto-decadal time scales (Putrasahan et al. 2016; Siqueira and

Corresponding author: Yu Cheng, yucheng@rsmas.miami.edu
Kirtman 2016). For instance, air-sea coupling at mesoscales can influence the wind energy input into the ocean and thus the circulation (Souza et al. 2014; Byrne et al. 2016; Renault et al. 2017b), as well as modify buoyancy fluxes as leakage waters travel across the Atlantic (Souza et al. 2011; Biastoch and Böning 2013).

The current generation of coupled climate models cannot resolve the mesoscale dynamics that are critical to forming an Agulhas retroflection (Biastoch et al. 2008b), resulting in an overestimation of leakage transport (42 Sv; $\left.1 \mathrm{~Sv} \equiv 10^{6} \mathrm{~m}^{3} \mathrm{~s}^{-1}\right)$ and a warm and salty bias in the South Atlantic (Weijer et al. 2012; Weijer and van Sebille 2014). Hence, we have developed a new coupled model configuration, the ocean-eddy-resolving $\left(0.1^{\circ}\right)$ Community Climate System Model, version 3.5 (CCSM3.5; Kirtman et al. 2012), which is able to simulate the Agulhas Current system realistically (Cheng et al. 2016). Unlike the same model with a $1.0^{\circ}$ ocean, the high-resolution CCSM3.5 produces a mean Agulhas leakage transport of $11.2 \mathrm{~Sv}$, well within the range of numerical and observational estimates of 3-20 Sv (Gordon et al. 1992; de Ruijter et al. 1999; Boebel et al. 2003; Doglioli et al. 2006; Richardson 2007; Biastoch et al. 2009; Le Bars et al. 2014). For the first time, we are able to investigate the sensitivity and 
influence of Agulhas leakage in a coupled climate system that includes the effects of ocean eddies. Throughout this paper, we will refer to CCSM3.5 as eddy resolving while acknowledging that this may not be the case at higher latitudes.

Many studies have assumed that the majority of Agulhas leakage is carried by intermittent Agulhas rings. Identifying ringlike structures using satellite altimetry and in situ observations has been used to quantify leakage in the real ocean (de Ruijter et al. 1999; Souza et al. 2011; Wang et al. 2015). However, recent numerical studies using tracer or particle tracking methods suggest eddy structures carry less than half of leakage transport (Doglioli et al. 2006; Loveday et al. 2015; Cheng et al. 2016). And it is likely that the eddying and noneddying components of leakage variability are constrained by mechanisms acting at different time and space scales. Loveday et al. (2015) show that in a regional ocean model, the noneddy part of Agulhas leakage is closely correlated with the large-scale wind forcing and Cheng et al. (2016) show that, while on subannual time scales leakage variability depends on the formation of Agulhas rings, on interannual time scales monthly mean velocity fields capture $80 \%$ of leakage variability. These results imply that eddy structures may play a less important role than the background flow at climate time scales and we investigate this further by trying to separate the different scales of flow in CCSM3.5.

The Agulhas system, alongside other western boundary currents, is a "hotspot" for air-sea interaction, as evidenced by high correlations between SST and heat fluxes (Small et al. 2008). Locally, near the tip of Africa, synoptic systems tracking through the region can produce strong winds that lead to large heat loss from the ocean, which destabilizes and expands the atmospheric marine boundary layer, fuels low-level atmospheric heat and moisture content, and enhances moisture transport and convective precipitation (e.g., Walker and Mey 1988; Mey et al. 1990; Jury et al. 1993; Mason 1995). Farther upstream, the warm SST and strong SST gradients of the Agulhas Current jet have been associated with extreme weather events and with summertime coastal and inland rainfall over eastern South Africa (Reason 2001a,b; Rouault et al. 2002; Blamey and Reason 2009; Jury 2015; Nkwinkwa Njouodo et al. 2018). Coupled climate modes also modulate South African rainfall. El Niño typically correlates with dry conditions in austral summer over southeastern Africa via modifications of the Walker and Hadley circulations (e.g., Lindesay 1988; Fauchereau et al. 2009; Hoell et al. 2015), while ENSO, the southern annular mode (SAM), and South Atlantic SST anomalies have been shown to modulate winter rainfall near the southwestern Cape region by shifting midlatitude storm tracks (Reason et al. 2002; Reason and Jagadheesha 2005; Reason and Rouault 2005; Philippon et al. 2012). Given these sensitivities, it is not surprising that CMIP5 models simulate South African rainfall with mixed success. These models have warm biases in the South Atlantic resulting from excessive Agulhas leakage, weak SST fronts, and weak air-sea coupling caused by coarse ocean resolution (Dieppois et al. 2015). CCSM3.5, with its more realistic eddies and fronts, offers an opportunity to investigate the imprints of Agulhas leakage and SST on regional climate.

\section{Methods}

We employ the NCAR CCSM3.5. The outputs we analyze are from a twentieth-century climate change simulation that resolves oceanic mesoscales. This simulation started from the year 1941 and recently reached 2008. Here we take 40 years of output from 1961 to 2000 to avoid possible model drifts caused by initialization.

\section{a. CCSM3.5}

The CCSM3.5 [the predecessor of the Community Earth System Model (CESM)] is a general circulation model coupling various components, including the Community Atmosphere Model, version 4.0 (CAM4.0); Community Land Model, version 4.0 (CLM4.0); Parallel Ocean Program, version 2.0 (POP2); and Community Ice Code, version 4.0 (CICE4). CAM4.0 and CLM4.0 share the same horizontal resolution of $0.5^{\circ}$, while the former has 26 vertical levels (Gent et al. 2010). To resolve mesoscales in the Agulhas Current system, the POP2 is configured identically to McClean et al. (2011), which has $0.1^{\circ}$ horizontal resolution and 42 vertical levels. The system is initialized from a high-resolution simulation with a fixed year $2000 \mathrm{CO}_{2}$ forcing $(368.9 \mathrm{ppm})$. It is integrated for 10 years with a fixed year $1940 \mathrm{CO}_{2}$ level to reduce the initialization shock before observed twentieth-century $\mathrm{CO}_{2}$ forcing is applied. Further details about spinup process, model configurations and validation can be found in Kirtman et al. (2012) and Cheng et al. (2016).

\section{b. Lagrangian particle tracking using CMS}

Lagrangian particle tracking has been widely implemented to estimate the turbulent Agulhas leakage (Donners and Drijfhout 2004; Doglioli et al. 2006; Speich et al. 2006; Biastoch et al. 2008b, 2009; Durgadoo et al. 2013; Weijer and van Sebille 2014; van Sebille et al. 2018). Here, our Lagrangian tool is the Connectivity Modeling System (CMS) (Paris et al. 2013), previously used to quantify Agulhas leakage (Weijer et al. 2012), 
Tasman leakage (van Sebille et al. 2012), and Indonesian Throughflow (van Sebille et al. 2014). Particles are seeded at the location of the Agulhas Current Time series (ACT) mooring array at $34^{\circ} \mathrm{S}$ (Beal et al. 2015). We release particles into the Agulhas jet only, defined as the poleward transport out to the first maximum of the vertically integrated velocity beyond the half-width of the mean jet, after Beal et al. (2015). Only one particle is released per grid cell, tagged with the volume transport calculated from the local cross-sectional velocity and the gridcell size. All released particles are tracked for 5 years.

Following previous studies, leakage particles are defined as those particles that cross the Good Hope line and remain in the South Atlantic within 5 years of release (van Sebille et al. 2010; Biastoch et al. 2009). Particles may cross the Good Hope line multiple times when trapped inside an eddy, but only those that cross an odd number of times remain in the South Atlantic. By timing the particles' last crossing, and summing up corresponding volume transports of such particles at each time step, we create an Agulhas leakage time series. More details can be found in Cheng et al. (2016).

\section{c. Separating large-scale and eddy fields}

One of the big challenges in this work is in separating the eddy field from the large-scale field. There is no universally accepted approach and neither temporal nor spatial filtering can account for the eddy rectification effect (Rhines and Holland 1979). Perhaps most commonly, the "eddy" and "mean" fields are separated using temporal filters, as in our previous work (Cheng et al. 2016). Here we filter the eddy effects in the spatial domain, using the method adopted by Small et al. (2014). While this method does not separate the two scales cleanly, particularly in the case of the Agulhas system where the large-scale field is sustained by the resolved eddies, our objective is to highlight the component of leakage variability potentially driven by largescale forcing, such as the wind, from that driven by mesoscale features, such as oceanic instabilities. We believe this is instructive, since the former has potential predictability.

We make 500 passes using a nine-point smoother to remove scales of flow below $500 \mathrm{~km}$. At each grid point, a single pass of the smoother takes the weighted average of that point and its eight surrounding points. Near the coast, some of these eight surrounding points may be on land and excluded from the calculation. To examine the sensitivity of the spatial smoother near the coastline, we conducted sensitivity tests by shifting the coastline up to $30 \mathrm{~km}$ eastward and found that the velocity magnitude of the smoothed field is affected by less than $10 \%$ and can both increase and decrease. The large-scale features in the smoothed field remain unchanged.

This method is similar to Gaussian spatial smoothers that have been implemented in many studies (e.g., Chelton and Schlax 2003; Li et al. 2015; Renault et al. 2017a). The spatial spectra of the smoothed zonal and meridional velocity (Fig. 1) show that all spectra have steep slopes near $500 \mathrm{~km}$, indicating that features smaller than this are effectively removed. We define the smoothed fields as the large-scale, and the difference from the original fields as the eddy fields.

With large-scale and eddy fields now separated, we design three experiments to test the dependence of the interannual Agulhas leakage variability on eddy and ring formation (Fig. 2). For all cases, the large-scale fields are chronologically fixed, while the eddy fields are shuffled or shifted. In the "shuffling" case (ShufL), annual eddy fields are randomly shuffled before being added back to the large-scale fields. However, by doing so, we introduce a discontinuity of eddy fields at the end of each year. Therefore, we conduct two "shifting" experiments: ShiftA uses eddy fields from 1957 to 1996, while ShiftB uses eddy fields from 1953 to 1992 . To illustrate the effect of our three experiments on the flow field, Fig. 3 shows surface current speed snapshots on a randomly chosen day for the original field, smoothed field, and three experimental fields. The magnitude of surface current speed is much smaller after smoothing (Fig. 3b) and no eddies are present, while the Agulhas Current jet, retroflection, and return current are still visible, although weak and broad. Adding back the shifted and shuffled eddy fields (Figs. 3c-e) yields distinct total fields from the original case (Fig. 3a): the number of eddies along the Good Hope line differs, as well as the position of retroflection. Using the new total fields to advect Lagrangian particles, we then compare leakage variability from each case to that from the original velocity fields.

\section{d. Statistical analyses}

We apply a 24-month low-pass filter to the daily leakage time series to extract interannual variability. The significance of correlations between leakage time series from each experiment is assessed using the standard Student's $t$ test, with effective degrees of freedom estimated by the $e$-folding time scale of each time series. Expecting that the low-pass filter may introduce spurious correlation, we also conduct spectral analyses of the daily leakage time series and test their coherence. Spectral analyses are conducted using a multitaper approach from the jLab toolbox (Lilly 2017). 

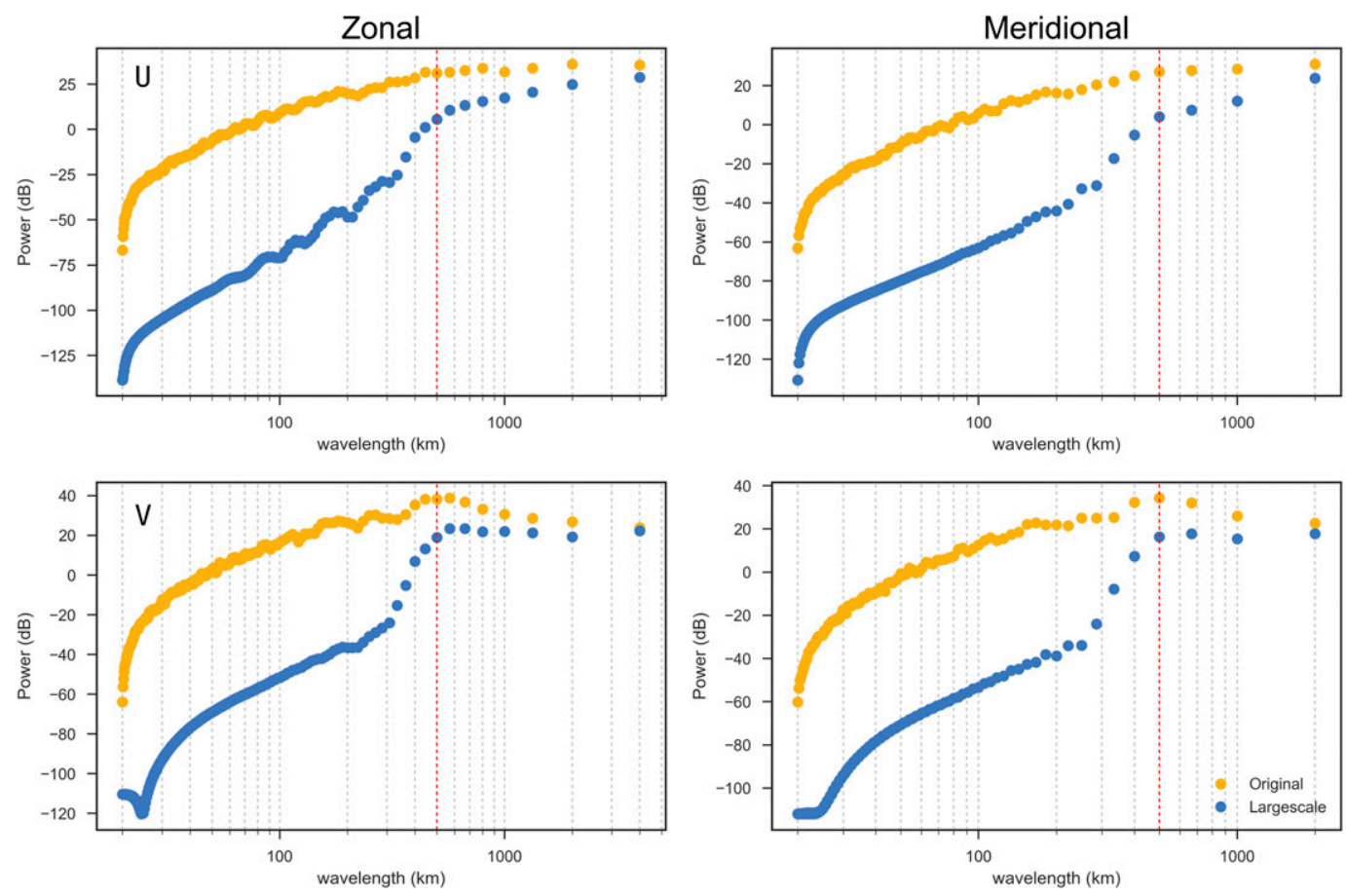

FIG. 1. (left) Zonal and (right) meridional spectra of (top) zonal and (bottom) meridional surface current velocity ( $U$ and $V$, respectively) before (yellow) and after (blue) spatial smoothing. The zonal spectra were calculated from meridionally averaged $U$ and $V$ in a box near the retroflection area $\left(35^{\circ}-45^{\circ} \mathrm{S}, 0^{\circ}-40^{\circ} \mathrm{E}\right)$. The meridional spectra were calculated from zonally averaged $U$ and $V$ in the box $35^{\circ}-50^{\circ} \mathrm{S}, 10^{\circ}-30^{\circ} \mathrm{E}$.

To investigate climate processes associated with leakage variability, we linearly regress several climate variables including sea level pressure, surface winds, surface temperature, salinity, and heat fluxes onto the low-passed leakage time series of the original case. All variables, including the leakage time series, are detrended before regression. The significance level of regression is assessed using the Student's $t$ test, as above.
We derive a SAM index from the principal component time series associated with the dominant empirical orthogonal function of $700-\mathrm{hPa}$ geopotential height, rather than following Marshall (2003) who used station-based sea level pressure observations. In this way, we account for an equatorward bias of Southern Hemisphere westerlies present in CCSM3.5, which is also found in many current-generation coupled models (Swart and Fyfe 2012).

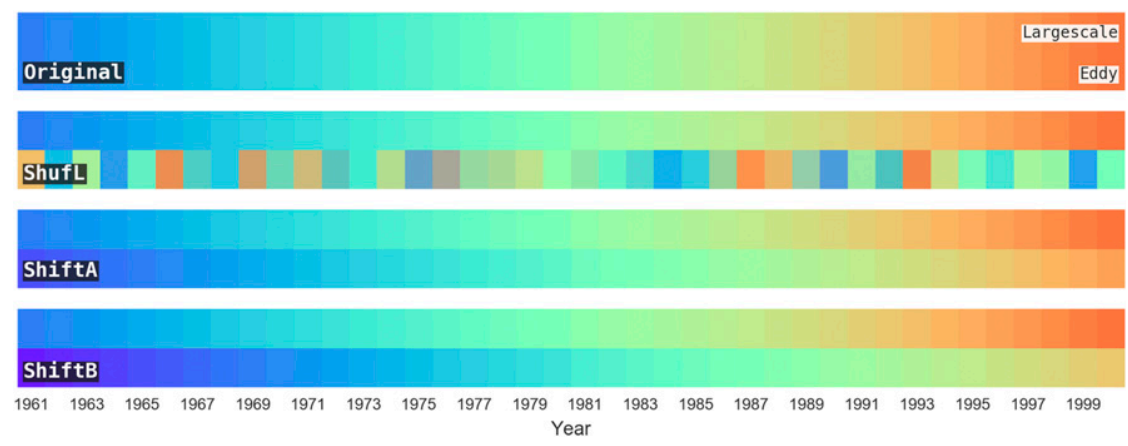

FIG. 2. Schematic diagram highlighting how the velocity fields used to advect Lagrangian particles are constructed. For each color bar, the upper half signifies the large-scale fields from 1961 to 2000, and the lower half marks the eddy fields. For ShufL, 40 years of eddy fields are randomly shuffled before being added back to the large-scale fields. For ShiftA and ShiftB, eddy fields are shifted backward for 4 and 8 years before being added back. 

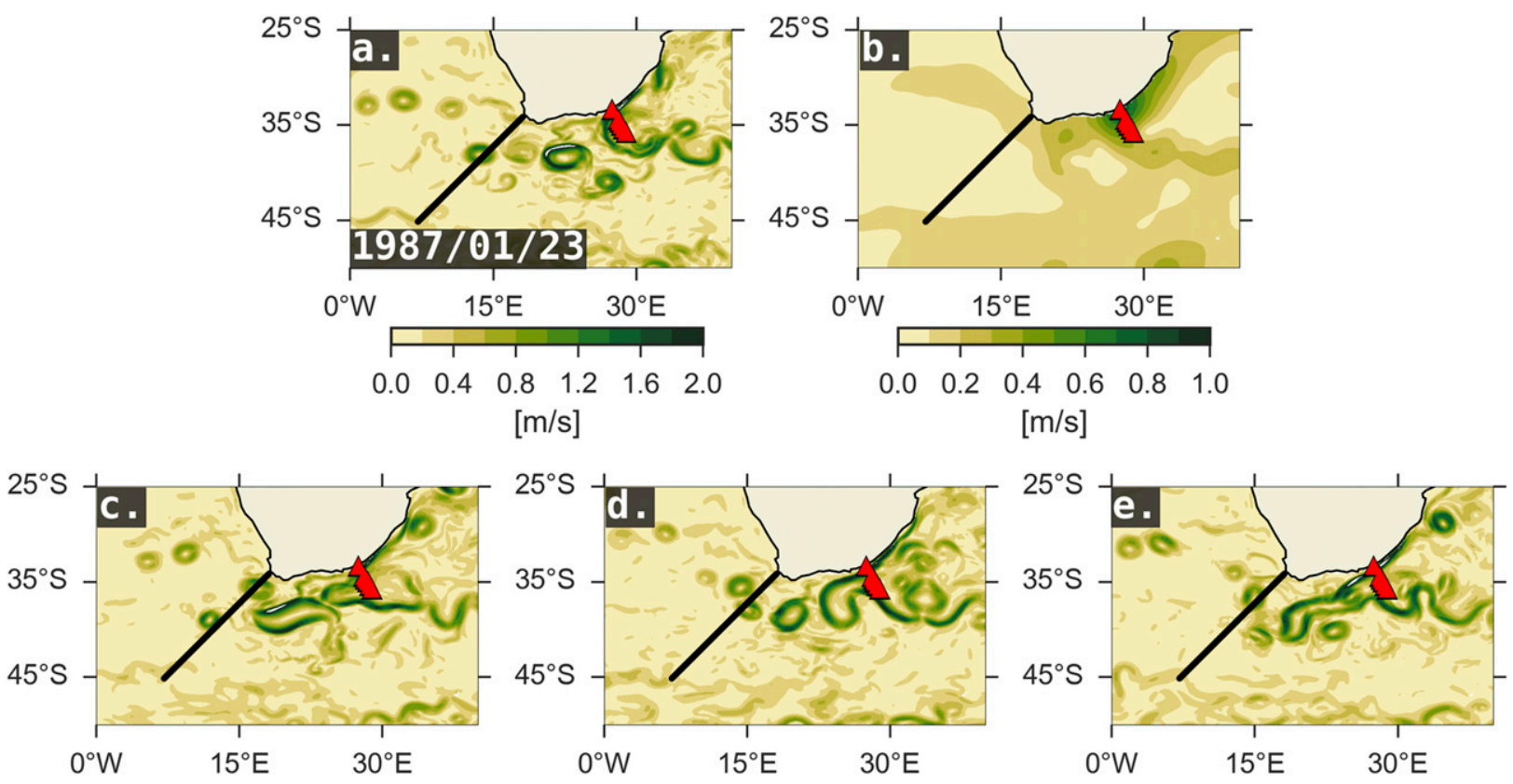

FIG. 3. Snapshots of surface current speed on 23 Jan 1987 for (a) the original velocity field, (b) the large-scale field after 500 passes of spatial smoothing, (c) ShufL, (d) ShiftA, and (e) ShiftB. The black solid line marks the approximation of the Good Hope line in the model, and the red partial triangles signify the Agulhas Current time series mooring array, where the Lagrangian particles are released.

Convective precipitation composites of high leakage years, defined as years with low-passed leakage value larger than its standard deviation, are used to show leakage-associated rainfall anomaly in different seasons. In CCSM3.5 three types of rainfall are recorded: largescale precipitation, convective precipitation, and total precipitation, which is the sum of the first two. We focus on convective precipitation because it can be directly linked to SST anomalies and therefore Agulhas leakage variability (Putrasahan et al. 2016; Nkwinkwa Njouodo et al. 2018). In the model, convective precipitation accounts for over half of total precipitation across most of southern Africa and the Mozambique Channel except during winter. Over the retroflection, convective precipitation accounts for over $40 \%$ of the total throughout the year (Fig. 4). Regression of large-scale precipitation to low-passed leakage time series shows a band of dry response between $30^{\circ}$ and $40^{\circ} \mathrm{S}$ less likely related to leakage-associated SST anomalies.

In reality, southern African rainfall is dominated by distinct systems seasonally. For example, the tropicaltemperate trough and associated cloud bands contribute a significant part of summer rainfall (Fauchereau et al. 2009), the cutoff lows are responsible for the major flood events in the transition seasons (Singleton and Reason 2007), and the winter rainfall region near the Cape is typically affected by cold fronts (Reason and Jagadheesha 2005). Coastal topography and teleconnection of climate modes add further complexity to South African climate variability and it is not trivial to relate each type of precipitation to specific systems.

\section{Results}

\section{a. Dependence of interannual leakage variability on the eddy field}

Agulhas leakage spectra from all experiments are significantly coherent at time scales longer than 1000 days, such that the large-scale forcing is dominating interannual variability (Fig. 5b), while the eddying structures (e.g., Agulhas rings, eddies) are important at time scales shorter than this. The spectra of daily leakage time series from each experiment are similar, with a flattening at low frequencies and an abrupt change in slope between 0.01 and 0.02 cycles per day (Fig. 5a). These frequencies relate to the shedding of Agulhas rings. In our simulation, about four rings pass through the Good Hope line each year, smaller than the $6 \mathrm{yr}^{-1}$ observed in the altimetry record (Elipot and Beal 2015), but typical for simulations of comparable resolution (Holton et al. 2017).

For the unmodified fields, the mean Agulhas leakage transport from 1966 to 2000 is $12.2 \mathrm{~Sv}$ (Fig. 6), slightly higher than the $11.2 \mathrm{~Sv}$ during the period from 1945 to 1970 (Cheng et al. 2016). For our three experiments, the low-passed leakage time series correlate with the original case at $r=0.62-0.69(P<0.01)$, 


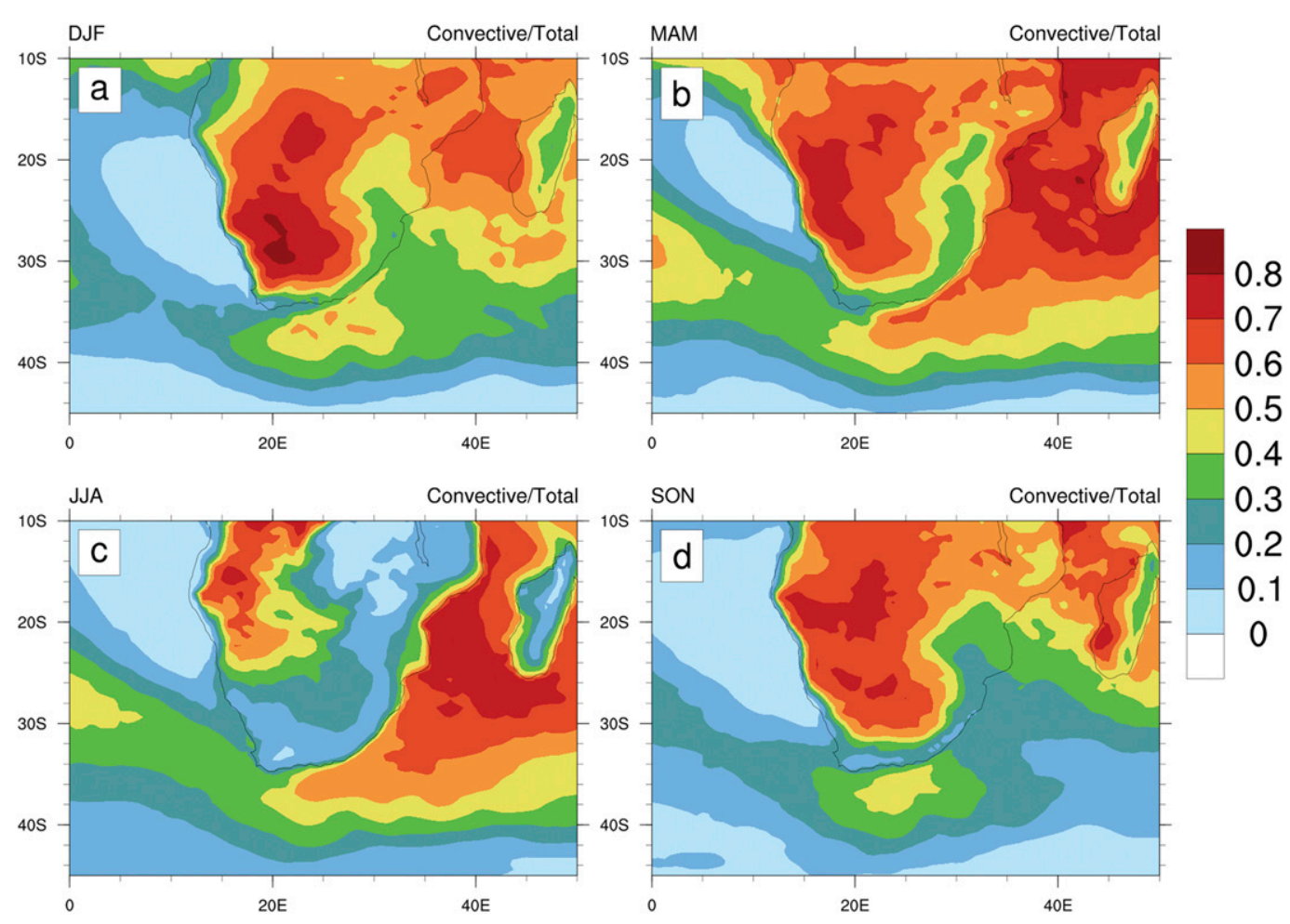

FIG. 4. Seasonal ratio of convective rainfall to total rainfall in CCSM: (a) austral summer (DJF), (b) autumn (MAM), (c) winter (JJA), and spring (d) SON.

implying that $40 \%-50 \%$ of leakage variability at interannual to decadal time scales is insensitive to the eddying structures. The leakage component that covaries between cases is likely attributed to the unchanged large-scale field, which is influenced by the large-scale wind forcing and hence has some predictability. It is perhaps surprising that a considerable amount of leakage variability is insensitive to eddies and ring shedding in one of the most turbulent areas of the World Ocean. However, this result concurs with previous analyses that obtained similar results using different eddy separation techniques (Loveday et al. 2015; Cheng et al. 2016). Acknowledging that the smoother cannot cleanly separate large-scale and eddy fields, our result implies that although leakage particles are mostly carried by individual eddying structures, large-scale forcing plays a significant role in modifying the interannual variability of Agulhas leakage.

In the real ocean, leakage is often estimated by studying Agulhas rings (de Ruijter et al. 1999). It has been understood that this method will tend to underestimate leakage transport because cyclonic eddies, filaments, and coastal jets are excluded. However, recent studies, focusing on coherent material eddies, show that Agulhas rings convey only a small fraction of the leakage transport (e.g., Wang et al. 2015). And our results, together with those of Loveday et al. (2015), stress that noneddy leakage transport is likely to be of first order. Therefore, Agulhas rings may be a poor proxy for leakage.

\section{b. Large-scale oceanic and atmospheric patterns associated with interannual leakage variability}

Using ocean models, leakage variability has been linked to shifting and intensification of the westerlies (de Ruijter et al. 1999; Rouault et al. 2009; Durgadoo et al. 2013; Loveday et al. 2014, 2015). We now test these relationships in our coupled model.

We find that a zonal wind pattern, with some similarities to the SAM, is related to interannual variability of Agulhas leakage (Fig. 7), where a positive leakage anomaly appears to be associated with a poleward shift and intensification of westerlies in the Indian Ocean and Atlantic sectors.

Our results largely corroborate previous findings using ocean models (Durgadoo et al. 2013; Loveday et al. 2015), except that the low-passed Agulhas leakage time series correlates poorly with the normalized SAM index in our model $(r=0.03)$. To explore further, Table 1 summarizes the linear relationships between Agulhas leakage and a number of indices representing 

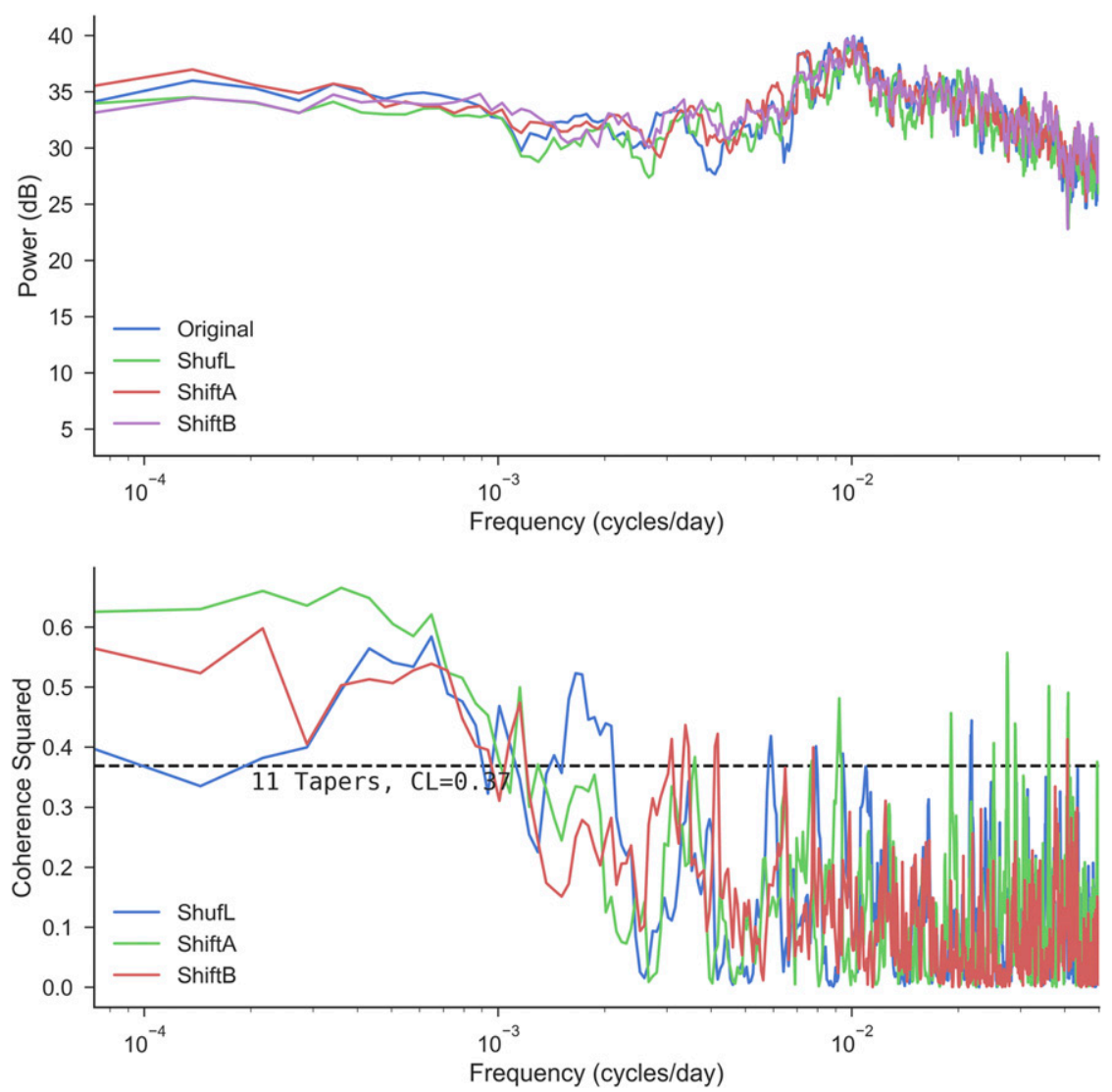

FIG. 5. (top) Spectra of Agulhas leakage transport time series from 1965 to 2000 for all four cases, and (bottom) coherence squared between three testing pairs, ShufL vs Original, ShiftA vs Original, and ShiftB vs Original. Spectra were taken using a multitaper approach with 11 tapers.

both large-scale ocean and atmospheric circulation. The zonal wind stress intensity and latitudinal position indices are defined following Swart and Fyfe (2012), as the maximum zonal-mean zonal wind stress and its latitude between $20^{\circ}$ and $70^{\circ} \mathrm{S}$. We calculated the subtropical Indian Ocean wind stress curl (WSC) after Loveday et al. (2015), defined as the area average within a box spanning $47^{\circ}-35^{\circ} \mathrm{S}, 20^{\circ}-115^{\circ} \mathrm{E}$. We find that the position of maximum westerly wind stress does not seem to influence leakage transport, while higher WSC and maximum westerly wind stress are associated with a positive leakage anomaly. This result is consistent with both Durgadoo et al. (2013) who showed that leakage is more responsive to the intensity than to the position of westerlies, and with Loveday et al. (2015) who found that the noneddying component of leakage correlates well with Indian Ocean WSC.

A prominent high pressure center in the southwestern Indian Ocean and corresponding anticyclonic surface winds are associated with a positive leakage anomaly (Fig. 8a). There are easterly anomalies on the northern flank of the anomalous high pressure center between $30^{\circ}$ and $40^{\circ} \mathrm{S}$, and the westerlies strengthen on the southern flank, reflected in the regression pattern shown in Fig. 7. Intensifying westerlies near $50^{\circ} \mathrm{S}$ coincide with the westerly jet core, leading to a local positive wind stress curl and a Sverdrupian increase of Agulhas leakage. The lack of direct correlation between leakage variability and the latitudinal position of the westerlies seems to contradict these results but it is because the change in the westerlies over the Pacific sector is likely superimposed by wind changes related to ENSO (Fig. 7). When zonally averaged over $0^{\circ}-70^{\circ} \mathrm{E}$, both maximum westerly wind stress and its latitudinal position significantly correlate with leakage variability.

Leakage has no clear correlation with either the strength of the Agulhas Current upstream nor the maximum speed of the Agulhas Return Current (ARC). This result is 


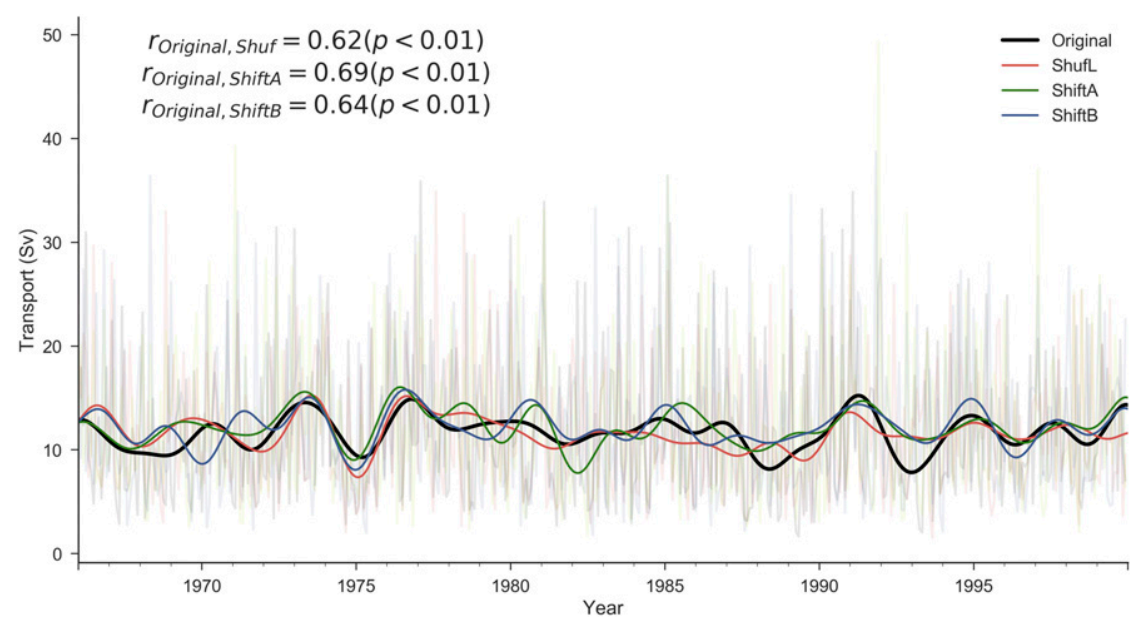

FIG. 6. Time series of Agulhas leakage transport from 1965 to 2000, monthly mean time series in the background. The 24-month low-pass-filtered time series are colored: the original case (black), ShufL (red), ShiftA (green), and ShiftB (blue).

inconsistent with the "inertial choking" theory, which would suggest an anticorrelation between the Agulhas Current and leakage (van Sebille et al. 2009). Loveday et al. (2014) also concluded that Agulhas leakage may be decoupled from the variability of the Agulhas Current at decadal time scales. However, using the retroflection index, defined as $R=1-\phi_{\mathrm{AL}} / \phi_{\mathrm{AC}}$ (Ou and De Ruijter 1986; de Ruijter et al. 1999; Le Bars et al. 2013), instead of the absolute leakage transport, we find that the index is significantly correlated with Agulhas Current transport in CCSM3.5 at interannual time scales.

\section{c. Regional climate imprints and seasonal precipitation response}

Based on linear regression, we find several regional climate patterns associated with interannual leakage variability (Fig. 8). The SST response to the high leakage anomaly shows an east-west contrast. In the southwest
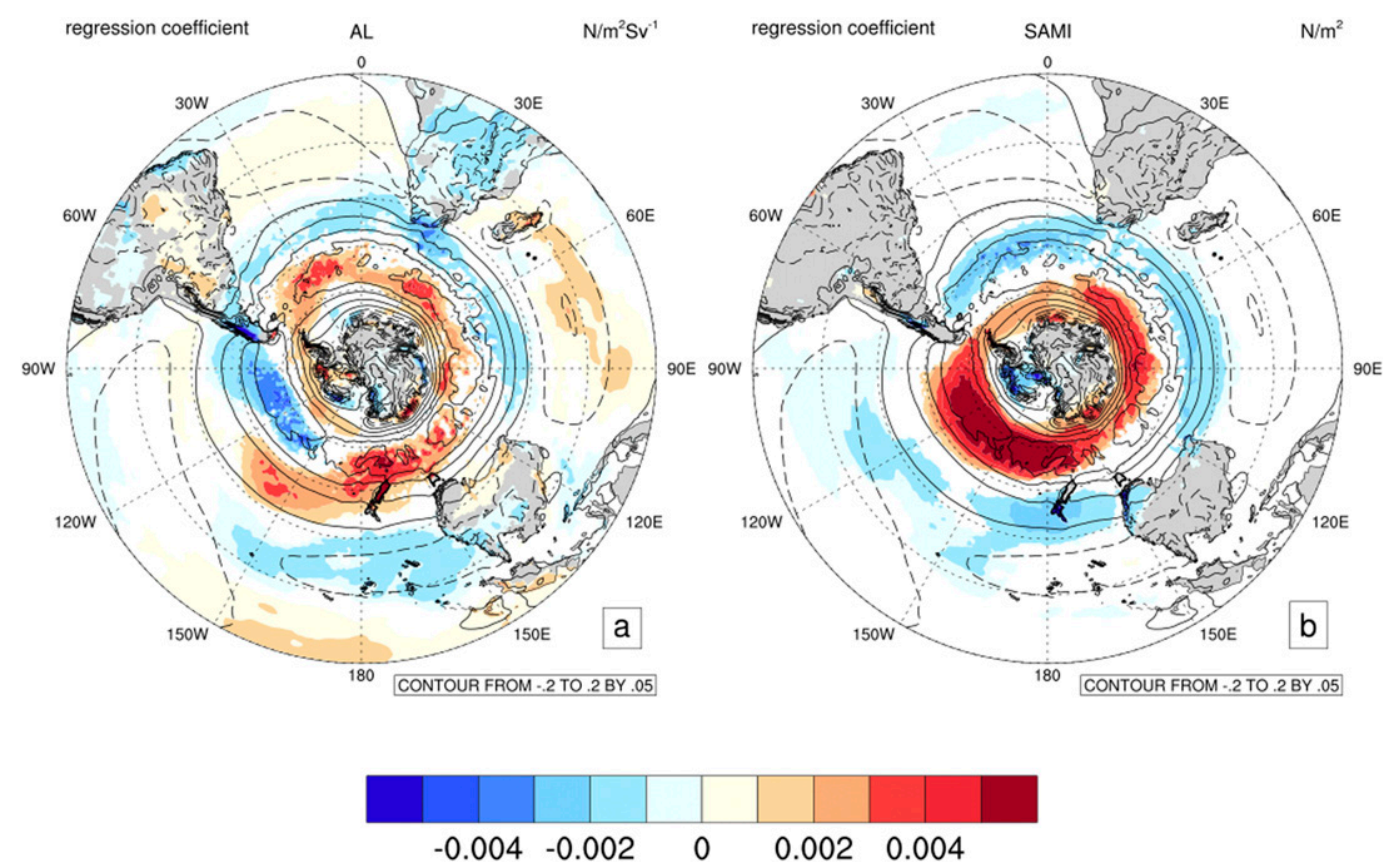

FIG. 7. Zonal wind stress response to (a) 24-month low-pass-filtered Agulhas Leakage time series and (b) simulated southern annular mode index derived from the dominant EOF of 700-hPa geopotential height south of $20^{\circ} \mathrm{S}$. The contours represent the mean westerly wind stress from 1961 to 2000. 
TABLE 1. Linear regression to 24-month low-pass-filtered Agulhas leakage transport from 1965 to 2000. All indices are detrended and low-pass filtered.

\begin{tabular}{lccc}
\hline \hline \multicolumn{1}{c}{ Name } & Mean \pm std dev & Sign & Significant $(p<0.1)$ \\
\hline Agulhas Current & $108.5 \pm 5.5 \mathrm{~Sv}$ & - & No \\
Agulhas Return Current max speed & $11.7 \pm 1.6 \mathrm{~ms}^{-1}$ & - & No \\
Southern annular mode index & $0.04 \pm 0.3$ & - & No \\
Max westerly wind stress & $0.2 \pm 0.01 \mathrm{Nm}^{-2}$ & + & Yes \\
Latitude of max westerly wind stress & $-53.0^{\circ} \pm 1.1^{\circ}$ & - & No \\
Max westerly wind stress $\left(0^{\circ}-70^{\circ} \mathrm{E}\right)$ & $0.2 \pm 0.05 \mathrm{Nm}^{-2}$ & $+\quad$ & Yes $(p<0.01)$ \\
Latitude of max westerly wind stress $\left(0^{\circ}-70^{\circ} \mathrm{E}\right)$ & $-52.0^{\circ} \pm 3.3^{\circ}$ & - & Yes $(p<0.01)$ \\
Indian Ocean wind stress curl & $9.3 \times 10^{-8} \pm 7.2 \times 10-\mathrm{N} \mathrm{m}^{-3}$ & $+\quad$ Yes \\
\hline
\end{tabular}

Indian Ocean SST decreases, while in the southeast Atlantic and over the retroflection SST increases. Similar patterns exist in both sensible and latent heat fluxes related to positive leakage anomalies (Figs. 8c,d): higher SST leads to stronger evaporation and air-sea temperature difference. Based on a similar pattern, Biastoch et al. (2015) constructed a 144-yr leakage proxy using historical SST observations to show that leakage has been increasing in recent decades. In their study, two ocean models and a coupled model of similar resolutions to ours share the same SST feature, indicating that this pattern is robust across models. We also find that higher surface salinity throughout the Agulhas Current system is an indicator of stronger Agulhas leakage (Fig. 8e). In the Cape basin, increasing evaporation and leakage leads to a saltier sea surface, while the positive anomaly upstream in the Agulhas Current may result from decreasing precipitation and increasing advection corresponding to a strengthening Agulhas Current.

The convective precipitation regression pattern resembles that of the SST and heat fluxes (Fig. 8f, note that the color scale is reversed). In the retroflection area, the higher SST during high leakage periods induces a positive precipitation anomaly, while a prominent negative precipitation anomaly over the southwest Indian Ocean $\left(30^{\circ}-42^{\circ} \mathrm{S}, 25^{\circ}-40^{\circ} \mathrm{E}\right)$ and the southeastern African coast $\left(20^{\circ}-30^{\circ} \mathrm{S}, 30^{\circ}-40^{\circ} \mathrm{E}\right)$ is related to cold SSTs. Interestingly, the precipitation response over the cold temperature anomaly has larger amplitude and spreads wider than that over the warm temperature anomaly, possibly because of the reduced moisture advection associated with poleward shifted westerlies. A similar pattern can be seen in the latent heat regression map (Fig. 8c).

The linear relation between SST and convective rainfall can be assessed by regressing the rainfall to the area-averaged SST in two prescribed boxes based on the surface temperature regression pattern (Fig. 8b). The warm SST anomaly in the retroflection area is linked to a wet anomaly extending northeastward along the Agulhas Current to near $30^{\circ} \mathrm{S}$ (Fig. 9a) and to dry conditions inland $\left(20^{\circ}-25^{\circ} \mathrm{S}\right)$ and in the southwest Indian Ocean $\left(30^{\circ}-42^{\circ} \mathrm{S}, 25^{\circ}-40^{\circ} \mathrm{E}\right)$. On the other hand, a positive SST anomaly in the cold box is associated with wet anomalies directly above and over southeastern Africa $\left(20^{\circ}-42^{\circ} \mathrm{S}, 20^{\circ}-40^{\circ} \mathrm{E}\right)$ (Fig. 9b). During high-leakage periods, the temperature anomaly in the cold box reinforces the dipole pattern related to the positive anomaly in the warm box, resulting in an asymmetric dipole, with the drying condition more widespread. Rain bands are often anchored to the warmer side of fronts in the Gulf Stream and Kuroshio Extension (Small et al. 2008; Minobe et al. 2008; Kuwano-Yoshida et al. 2010). Because the reduced precipitation in the cold box occurs over the Agulhas Return Current frontal zones, we suspect that the dry anomaly could be partially attributed to the relaxation of the meridional SST gradient in the region, in addition to the direct SST effect.

Although the dipole regression pattern of SST appears very local (Fig. 8b), we find another area of cold anomaly with a smaller magnitude around $20^{\circ}-30^{\circ} \mathrm{S}$, $30^{\circ}-60^{\circ} \mathrm{E}$, collocated with negative specific humidity (not shown). This cool anomaly partially resembles the subtropical dipole pattern of the southern Indian Ocean (Behera and Yamagata 2001). Through a set of atmospheric general circulation model (AGCM) experiments driven by prescribed SST fields, Reason (2001b) explored the effects of such SST patterns and reported that the warm pool in the southwest Indian Ocean may induce anomalous cyclonic surface winds and enhance moisture convergence and rainfall over large areas of southeastern Africa. Similar relationships between inland rainfall and neighboring subtropical SST have been suggested by earlier studies (Walker 1990; Mason 1995; Reason and Mulenga 1999). It is likely that subtropical dipole and Agulhas leakage SST and their effects on rainfall are interdependent. It would be interesting to conduct similar AGCM experiments using the leakage-associated SST pattern as the forcing field to isolate leakage effects. 

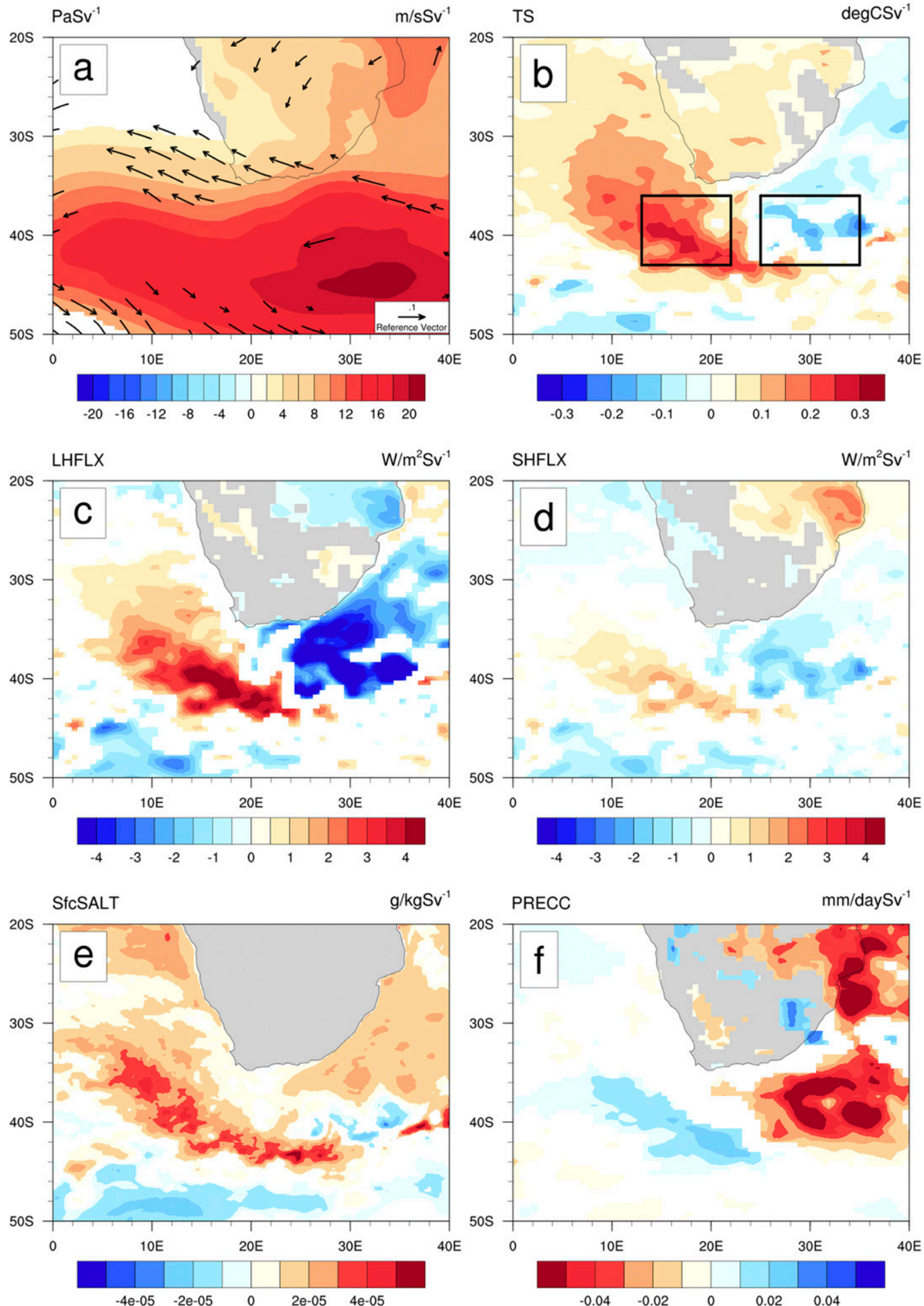

FIG. 8. Regional climate imprints of interannual Agulhas leakage variability: regression of climate variables to the original low-pass-filtered leakage time series. (a) Sea level pressure and 10-m wind vectors; (b) surface temperature, with two boxes signifying the averaging areas used in precipitation regression to sea surface temperature (Figs. 9a,b); (c) surface latent heat flux; (d) surface sensible heat flux, positive into the atmosphere; (e) sea surface salinity; and (f) convective precipitation rate. Only the areas with significant correlations $(p<0.05)$ are plotted. 

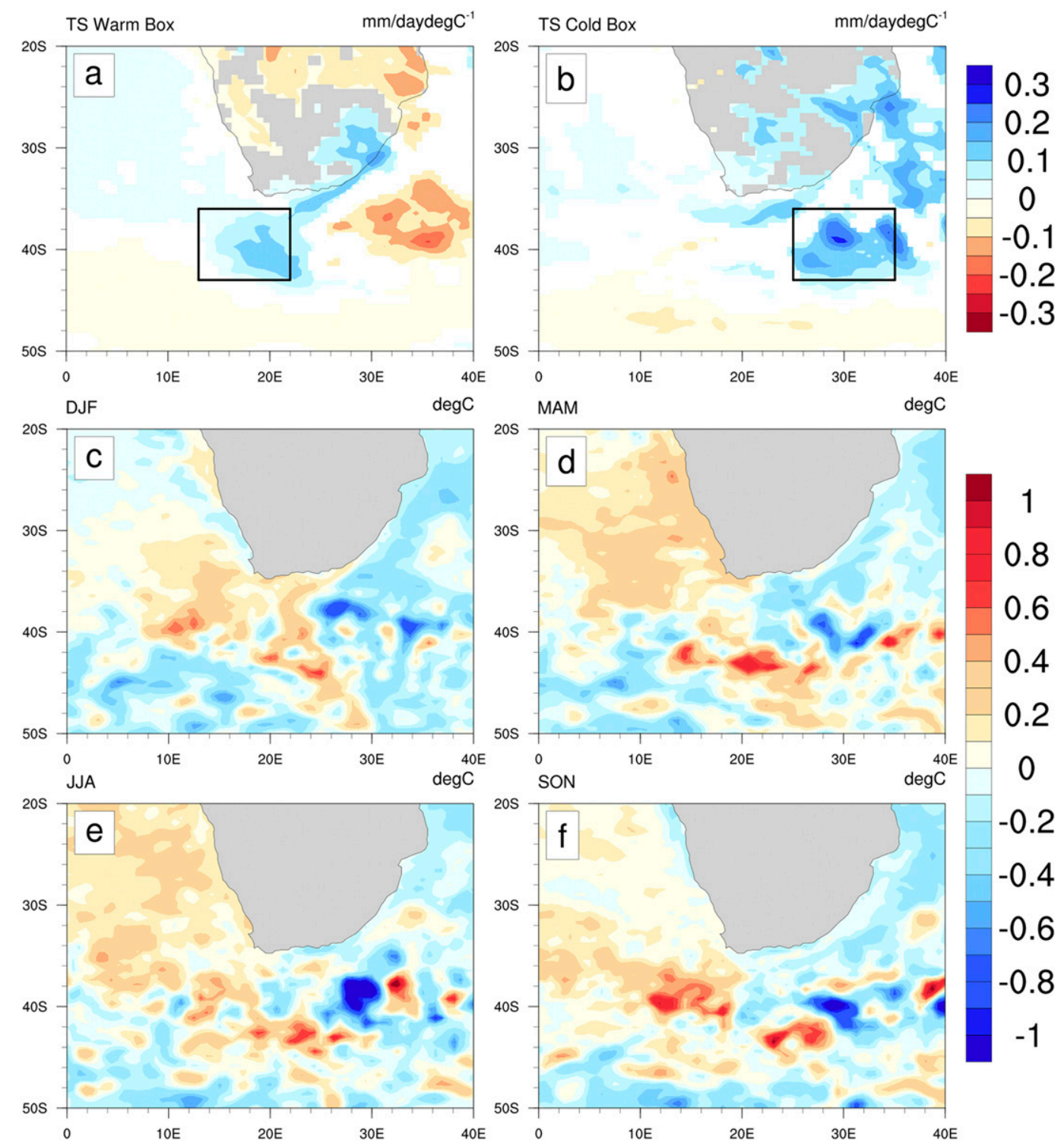

FIG. 9. Convective precipitation regressed to area-average surface temperature in the (a) warm box $\left(36^{\circ}-43^{\circ} \mathrm{S}\right.$, $\left.13^{\circ}-22^{\circ} \mathrm{E}\right)$ and (b) cold box $\left(36^{\circ}-43^{\circ} \mathrm{S}, 25^{\circ}-35^{\circ} \mathrm{E}\right)$. (c)-(f) Seasonal composite of sea surface temperature of high leakage years, defined as the years with leakage anomaly greater than one standard deviation (1.6 Sv). Years 1972, 1973, 1974, 1976, 1977, 1990, 1991, 1995, and 1999 are selected.

Other rainfall studies have focused specifically on the effects of Agulhas Current SST gradients, by comparing AGCM experiments driven by smoothed and nonsmoothed SST fields (Reason 2001a; Nkwinkwa Njouodo et al. 2018). Reason (2001a) found a similar large-scale atmospheric response as found in the warm pool-SST experiments, although of the opposite sign, with the influence of the Agulhas Current more prominent in austral winter because of the larger airsea temperature contrast. On the other hand, using a higher-resolution model, Nkwinkwa Njouodo et al. (2018) find that the influence of the Agulhas Current is very local, as shown by a collocated narrow band of low-level convergence and rainfall, and that impacts on terrestrial rainfall are greatest in summer, rather than in winter.

Regions of southern Africa show significant rainfall seasonality. While most of southern Africa receives most rainfall in austral summer, the southwestern coastal area is dominated by winter rainfall associated with synoptic systems such as cold fronts and cutoff lows (Reason et al. 2002; Reason and Jagadheesha 2005; Singleton and Reason 2006, 2007; Rouault et al. 2010; Philippon et al. 2012). To discern the effects of leakage-related SST 

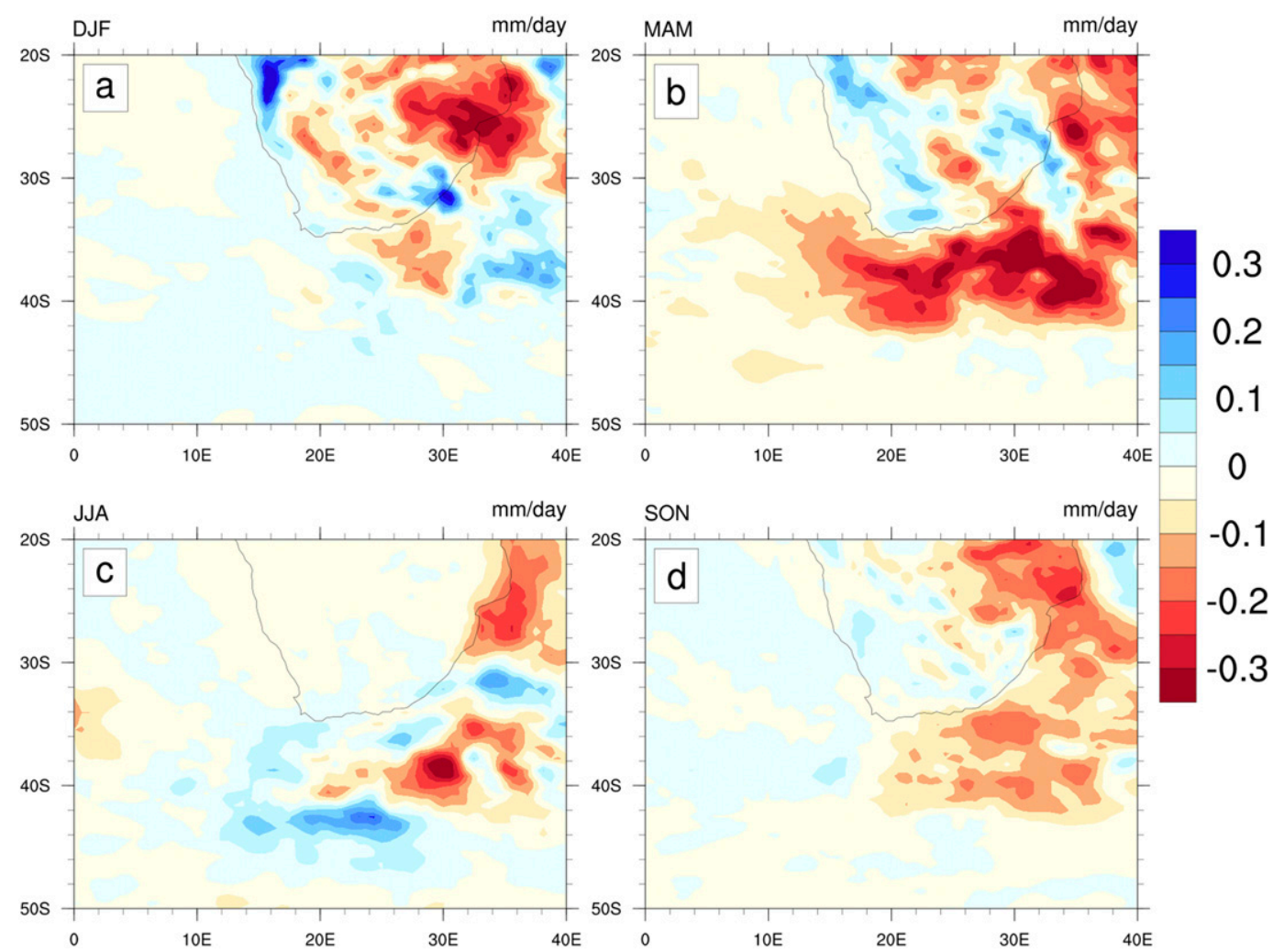

FIG. 10. Seasonal composite of convective precipitation of high leakage years, defined as the years with leakage anomaly greater than one standard deviation (1.6 Sv): (a) austral summer (DJF), (b) autumn (MAM), (c) winter (JJA), and (d) spring (SON). Years 1972, 1973, 1974, 1976, 1977, 1990, 1991, 1995, and 1999 are selected.

anomaly in different seasons, we calculate the seasonal composite of several variables during high leakage years.

A familiar east-west contrasting pattern persists throughout the year in SST seasonal composites (Figs. 9c-f), with the pattern from spring to summer most similar to the annual average (Fig. 8b). Unlike the SST, convective precipitation composites differ greatly between seasons (Fig. 10). Dry conditions over the return current during high leakage years are more prominent in transition seasons, but the reduced inland convective rainfall is most obvious in summer. The winter rainfall composite resembles its SST counterpart (Figs. 9e and 10c), possibly because of the high air-sea temperature difference in the winter months. These results suggest that SST alone cannot explain the leakage associated convective rainfall anomaly.

A similar analysis on sea level pressure (SLP, not shown) shows a strong positive anomaly to the south of Africa in transition seasons, similar to Fig. 8a. Strong subsidence associated with the high pressure anomaly could lead to the extended dry conditions in these seasons. A smaller high pressure anomaly appears on the southeastern coast of Africa in all seasons and contributes to the reduced convective rainfall near the coast. In summer, rainfall season for most of southern Africa, this high pressure anomaly occurs right over the area of maximum rainfall, leading to the strong dry anomaly in Fig. 10a. The areas of subsidence are clear in the seasonal $500-\mathrm{hPa}$ vertical velocity composite (Fig. 11a), coupled with a strong moisture divergence at $850 \mathrm{hPa}$ (Fig. 12a). Less moisture is transported onshore, possibly related to the cool anomaly over the southwestern Indian Ocean and the return current area. Using the NASA MERRA-2 (Gelaro et al. 2017) and a leakage proxy based on observed SST following Biastoch et al. (2015), the same composite analysis (with the proxy higher than one standard deviation) shows that the relationship between reduced summer convective rainfall and increased Agulhas leakage seems to hold in the real world (Fig. 13). However, in other seasons, the patterns differ greatly from those in CCSM3.5.

We find that part of the interannual rainfall variability is related to Agulhas leakage, which is associated 

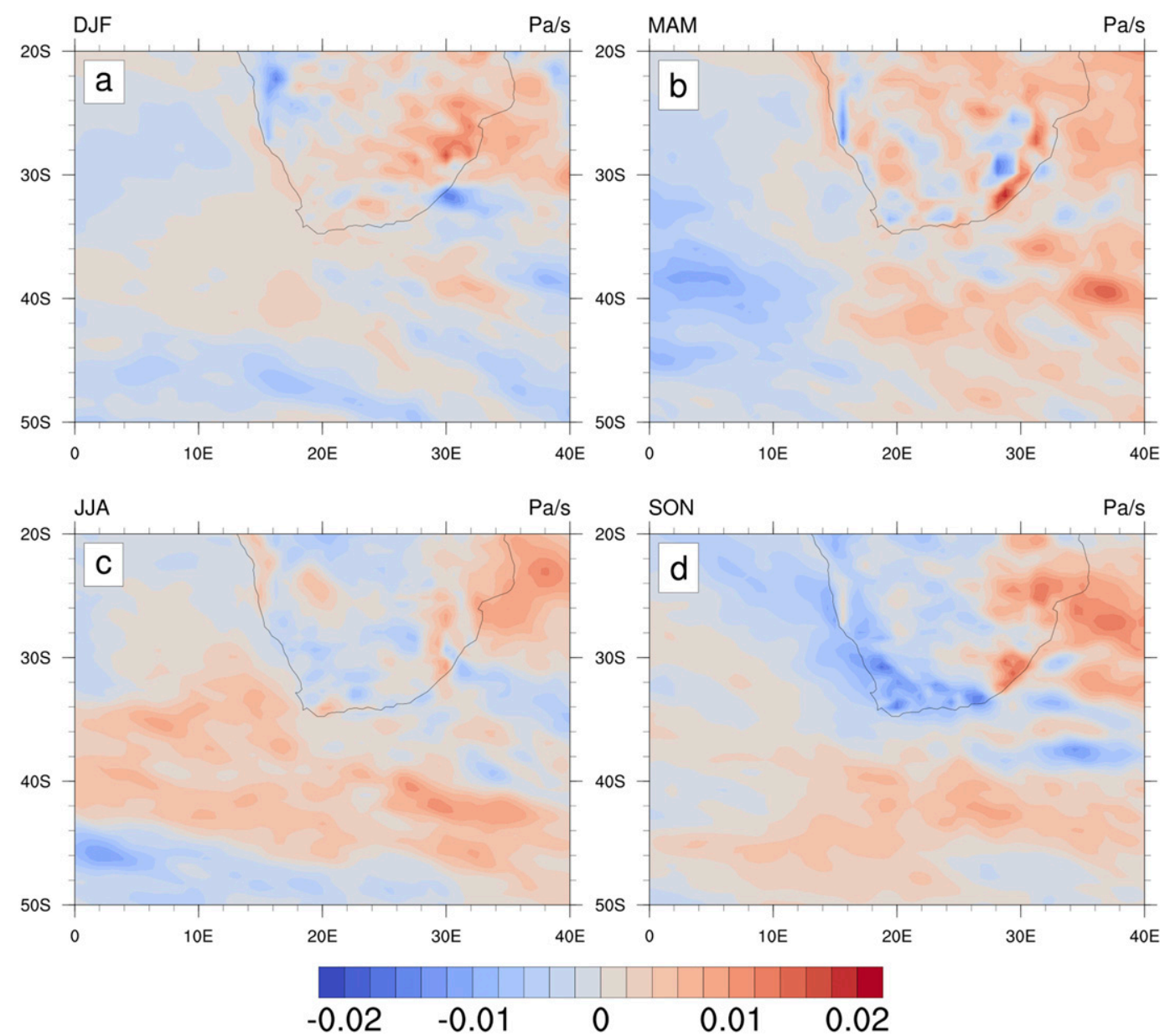

FIG. 11. Seasonal composite of 500-hPa vertical velocity of high leakage years, defined as the years with leakage anomaly greater than one standard deviation (1.6 Sv): (a) austral summer (DJF), (b) autumn (MAM), (c) winter (JJA), and (d) spring (SON). Years 1972, 1973, 1974, 1976, 1977, 1990, 1991, 1995, and 1999 are selected.

with local dipole patterns in SST, surface heat fluxes, and convective rainfall. However, associated patterns of sea level pressure, surface specific humidity, and $500-\mathrm{hPa}$ vertical motions are of much larger scales, pointing to a common large-scale modulator of the system like ENSO. We have focused on convective rainfall to highlight the local SST effects, yet the role of ENSO, through its influence on leakage variability (Putrasahan et al. 2016), on the large-scale SST patterns in the south Indian and Atlantic Oceans (Alexander et al. 2002; Fauchereau et al. 2009), and thus on the atmospheric circulation (Hoell et al. 2015), will be significant and deserves further study.

\section{Conclusions}

The interannual variability of Agulhas leakage is, for the first time, investigated in an ocean-eddy-resolving coupled model, CCSM3.5. Using a Lagrangian framework and damping the eddying flows with a spatial smoother, we demonstrate that half of Agulhas leakage variability at interannual time scales is insensitive to the formation of Agulhas rings. High leakage periods are related to a weakening of the westerlies around $35^{\circ} \mathrm{S}$ and a strengthening at their maximum around $50^{\circ} \mathrm{S}$, creating a band of increased wind stress curl to the south of Africa. A similar relationship has been suggested by previous OGCM studies at decadal time scales. Our results support the hypothesis that leakage is responding to changing westerlies as part of a large-scale circulation adjustment of the Southern Hemisphere supergyre (Durgadoo et al. 2013).

The CCSM3.5 provides the opportunity to explore the regional climate effects of Agulhas system variability. We find that increasing leakage correlates with increasing surface salinity throughout the Agulhas system, while SST, heat fluxes, and convective precipitation share a similar east-west contrast dipole. Although SST 

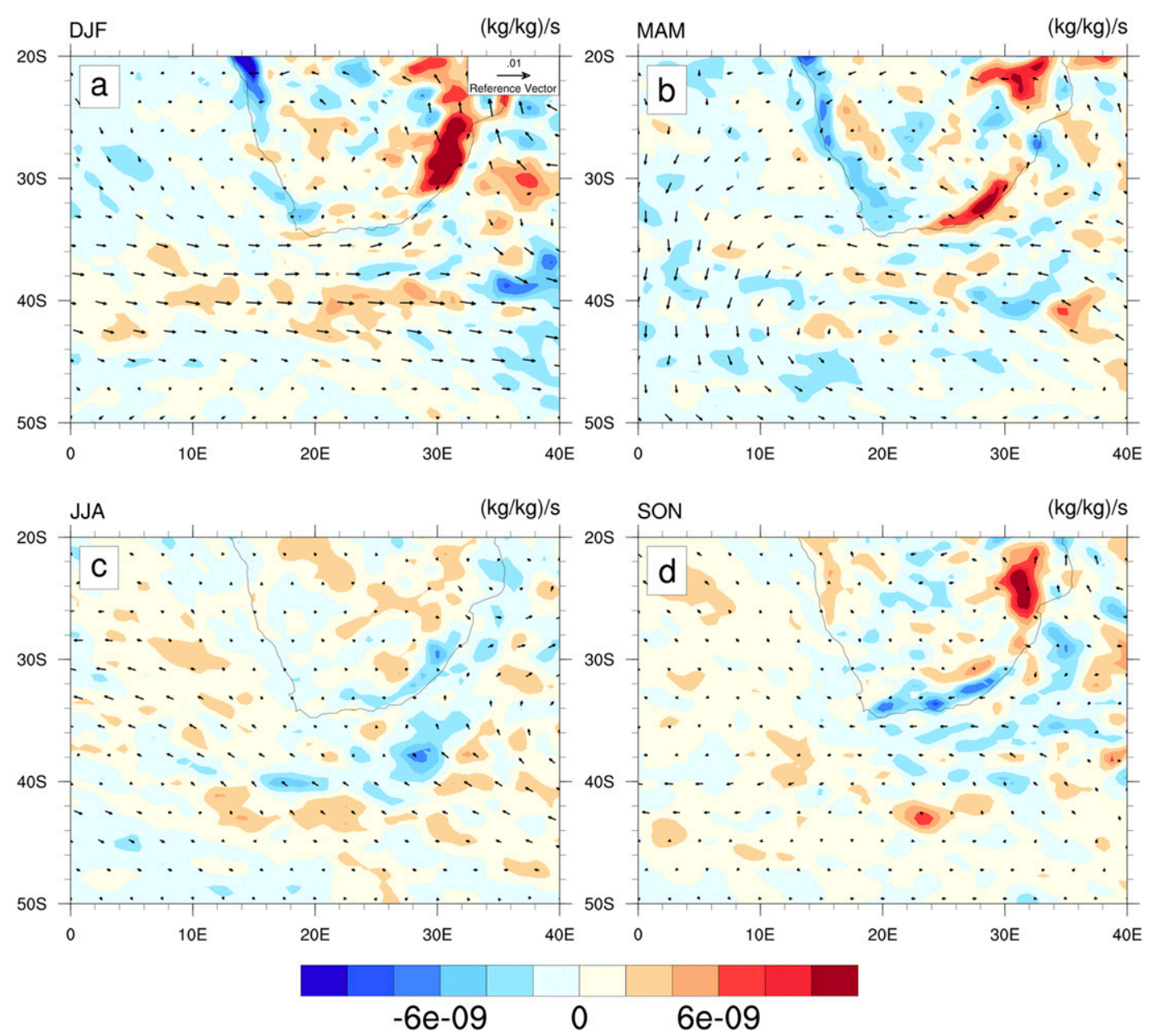

FIG. 12. Seasonal composite of 850-hPa moisture divergence (shaded) and moisture flux (vector) of high leakage years, defined as the years with leakage anomaly greater than one standard deviation (1.6 Sv): (a) austral summer (DJF), (b) autumn (MAM), (c) winter (JJA), and (d) spring (SON). Years 1972, 1973, 1974, 1976, 1977, 1990, 1991, 1995, and 1999 are selected.

response to increasing leakage is similar across seasons, the convective rainfall response has seasonal variation. The greatest reduction of inland convective rainfall occurs in austral summer, the major rainfall season for most of southern Africa.

Our results are based on linear analyses, yet links between the Agulhas system and South African rainfall may be modified by broader-scale climate modes such as ENSO (e.g., Lindesay 1988; Fauchereau et al. 2009; Hoell et al. 2015). For instance, Jury (2015) reported an anticorrelation between south African inland rainfall and SST variability associated with the Agulhas Current, but concluded that both are likely responding to the positive phase of ENSO. Our analysis is also limited to convective rainfall, neglecting likely effects of leakage-associated SST anomalies on the major summer rainfall system of southern Africa, the tropicaltemperate trough.
Agulhas leakage has drawn much attention because of its potential global climatic relevance tied to its influence on the Atlantic meridional overturning circulation. Our work has aimed to investigate the interannual variability of leakage, its relation to large-scale circulation, and its impacts on regional climate. Extrapolating our findings to the longer term, with the observed intensifying trend of the westerlies (Thompson and Solomon 2002; Marshall 2003; Swart and Fyfe 2012), it is likely that Agulhas leakage is increasing (Biastoch and Böning 2013; Biastoch et al. 2015; Loveday et al. 2015) and hence there may be a reducing trend in inland rainfall during the major rainfall season over southern Africa. This consequence is potentially important to the economies and societies of the region, because a significant rural population of southern Africa are dependent on rain-fed agriculture. However, the reported relation and the extrapolated trend may be offset by 


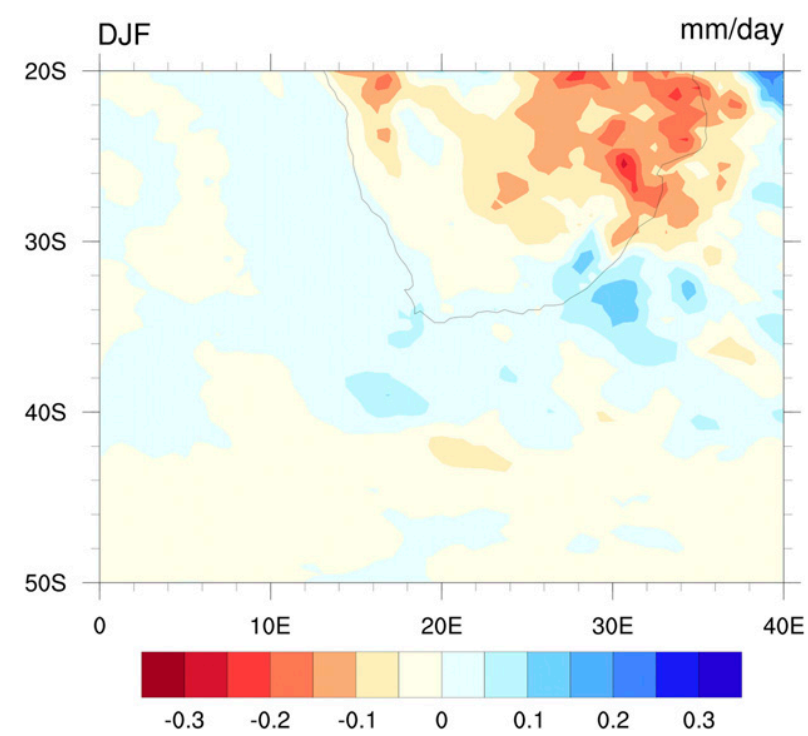

FIG. 13. Summer convective rainfall composite from NASA MERRA-2. The Agulhas leakage proxy in observation is based on area-averaged SST difference between two boxes (Fig. 8b) near the retroflection following Biastoch et al. (2015).

dominant modes such as ENSO and the SAM, or trends of the Hadley cell, and these deserve further study.

Acknowledgments. This research was supported by NSF Awards OCE1154986 and OCE1459543. BPK acknowledges funding support from NSF OCE1419569 and OCE1559151 and ONR N000141712136. CCSM outputs are on the University of Miami Center for Computational Science cluster named Pegasus, as well as on external hard drives. Data will be made available from the corresponding author upon request. We thank three anonymous reviewers for their insightful comments.

\section{REFERENCES}

Alexander, M. A., I. Bladé, M. Newman, J. R. Lanzante, N.-C. Lau, and J. D. Scott, 2002: The atmospheric bridge: The influence of ENSO teleconnections on air-sea interaction over the global oceans. J. Climate, 15, 2205-2231, https://doi.org/10.1175/1520-0442(2002) 015<2205:TABTIO > 2.0.CO;2.

Backeberg, B. C., J. A. Johannessen, L. Bertino, and C. J. Reason, 2008: The greater Agulhas Current system: An integrated study of its mesoscale variability. J. Oper. Oceanogr., 1, 29-44, https://doi.org/10.1080/1755876X.2008.11020093.

Beal, L. M., and Coauthors, 2011: On the role of the Agulhas system in ocean circulation and climate. Nature, 472, 429-436, https://doi.org/10.1038/nature09983.

— , S. Elipot, A. Houk, and G. M. Leber, 2015: Capturing the transport variability of a western boundary jet: Results from the Agulhas Current Time-Series Experiment (ACT). J. Phys. Oceanogr., 45, 1302-1324, https://doi.org/10.1175/JPO-D-14-0119.1.

Behera, S. K., and T. Yamagata, 2001: Subtropical SST dipole events in the southern Indian Ocean. Geophys. Res. Lett., 28, 327-330, https://doi.org/10.1029/2000GL011451.
Biastoch, A., and C. W. Böning, 2013: Anthropogenic impact on Agulhas leakage. Geophys. Res. Lett., 40, 1138-1143, https:// doi.org/10.1002/grl.50243.

— - — , and J. R. E. Lutjeharms, 2008a: Agulhas leakage dynamics affects decadal variability in Atlantic overturning circulation. Nature, 456, 489-492, https://doi.org/10.1038/nature07426.

—, J. R. E. Lutjeharms, C. W. Böning, and M. Scheinert, 2008b: Mesoscale perturbations control inter-ocean exchange south of Africa. Geophys. Res. Lett., 35, L20602, https://doi.org/ 10.1029/2008GL035132.

—, C. W. Böning, F. U. Schwarzkopf, and J. R. E. Lutjeharms, 2009: Increase in Agulhas leakage due to poleward shift of Southern Hemisphere westerlies. Nature, 462, 495-498, https:// doi.org/10.1038/nature08519.

— J. V. Durgadoo, A. K. Morrison, E. van Sebille, W. Weijer, and S. M. Griffies, 2015: Atlantic multi-decadal oscillation covaries with Agulhas leakage. Nat. Commun., 6, 10082, https://doi.org/10.1038/ncomms10082.

Blamey, R. C., and C. J. C. Reason, 2009: Numerical simulation of a mesoscale convective system over the east coast of South Africa. Tellus, 61A, 17-34, https://doi.org/10.1111/j.16000870.2008.00366.x.

Boebel, O., J. Lutjeharms, C. Schmid, W. Zenk, T. Rossby, and C. Barron, 2003: The Cape Cauldron: A regime of turbulent interocean exchange. Deep-Sea Res. II, 50, 57-86, https://doi.org/ 10.1016/S0967-0645(02)00379-X.

Byrne, D., M. Münnich, I. Frenger, and N. Gruber, 2016: Mesoscale atmosphere ocean coupling enhances the transfer of wind energy into the ocean. Nat. Commun., 7, ncomms11867, https://doi.org/10.1038/ncomms11867.

Castellanos, P., E. J. D. Campos, I. Giddy, and W. Santis, 2016: Inter-comparison studies between high-resolution HYCOM simulation and observational data: The South Atlantic and the Agulhas leakage system. J. Mar. Syst., 159, 76-88, https://doi.org/ 10.1016/j.jmarsys.2016.02.010.

Chelton, D. B., and M. G. Schlax, 2003: The accuracies of smoothed sea surface height fields constructed from tandem satellite altimeter datasets. J. Atmos. Oceanic Technol., 20, 1276-1302, https://doi.org/ 10.1175/1520-0426(2003)020<1276:TAOSSS > 2.0.CO;2.

Cheng, Y., D. Putrasahan, L. Beal, and B. Kirtman, 2016: Quantifying Agulhas leakage in a high-resolution climate model. J. Climate, 29, 6881-6892, https://doi.org/10.1175/JCLI-D-15-0568.1.

de Ruijter, W. P. M., A. Biastoch, S. S. Drijfhout, J. R. E. Lutjeharms, R. P. Matano, T. Pichevin, P. J. Van Leeuwen, and W. Weijer, 1999: Indian-Atlantic interocean exchange: Dynamics, estimation and impact. J. Geophys. Res., 104, 20 885-20 910, https:/doi.org/ 10.1029/1998JC900099.

Dieppois, B., M. Rouault, and M. New, 2015: The impact of ENSO on Southern African rainfall in CMIP5 ocean atmosphere coupled climate models. Climate Dyn., 45, 2425-2442, https:// doi.org/10.1007/s00382-015-2480-x.

Doglioli, A. M., M. Veneziani, B. Blanke, S. Speich, and A. Griffa, 2006: A Lagrangian analysis of the Indian-Atlantic interocean exchange in a regional model. Geophys. Res. Lett., 33, L14611, https://doi.org/10.1029/2006GL026498.

Donners, J., and S. S. Drijfhout, 2004: The Lagrangian view of South Atlantic interocean exchange in a global ocean model compared with inverse model results. J. Phys. Oceanogr., 34, 1019-1035, https://doi.org/10.1175/1520-0485(2004)034<1019: TLVOSA $>2.0 . \mathrm{CO} ; 2$.

Durgadoo, J. V., B. R. Loveday, C. J. C. Reason, P. Penven, and A. Biastoch, 2013: Agulhas leakage predominantly responds to the Southern Hemisphere westerlies. J. Phys. Oceanogr., 43, 2113-2131, https://doi.org/10.1175/JPO-D-13-047.1. 
Elipot, S., and L. M. Beal, 2015: Characteristics, energetics, and origins of Agulhas Current meanders and their limited influence on ring shedding. J. Phys. Oceanogr., 45, 2294-2314, https://doi.org/ 10.1175/JPO-D-14-0254.1.

Fauchereau, N., B. Pohl, C. J. C. Reason, M. Rouault, and Y. Richard, 2009: Recurrent daily OLR patterns in the Southern Africa/Southwest Indian Ocean region, implications for South African rainfall and teleconnections. Climate Dyn., 32, 575-591, https://doi.org/10.1007/s00382-008-0426-2.

Gelaro, R., and Coauthors, 2017: The Modern-Era Retrospective Analysis for Research and Applications, Version 2 (MERRA-2). J. Climate, 30, 5419-5454, https://doi.org/10.1175/JCLI-D16-0758.1.

Gent, P. R., S. G. Yeager, R. B. Neale, S. Levis, and D. A. Bailey, 2010: Improvements in a half degree atmosphere/land version of the CCSM. Climate Dyn., 34, 819-833, https://doi.org/ 10.1007/s00382-009-0614-8.

Gordon, A. L., 1986: Interocean exchange of thermocline water. J. Geophys. Res., 91, 5037-5046, https://doi.org/10.1029/JC091iC04p05037.

— , R. F. Weiss, W. M. Smethie, and M. J. Warner, 1992: Thermocline and intermediate water communication between the South Atlantic and Indian Oceans. J. Geophys. Res., 97, 7223-7240, https://doi.org/10.1029/92JC00485.

Hoell, A., C. Funk, T. Magadzire, J. Zinke, and G. Husak, 2015: El Niño-Southern Oscillation diversity and Southern Africa teleconnections during austral summer. Climate Dyn., 45, 1583-1599, https://doi.org/10.1007/s00382-014-2414-z.

Holton, L., J. Deshayes, B. C. Backeberg, B. R. Loveday, J. C. Hermes, and C. J. C. Reason, 2017: Spatio-temporal characteristics of Agulhas leakage: A model inter-comparison study. Climate Dyn., 48, 2107-2121, https://doi.org/10.1007/s00382-016-3193-5.

Jury, M. R., 2015: Passive suppression of South African rainfall by the Agulhas Current. Earth Interact., 19, https://doi.org/ 10.1175/EI-D-15-0017.1.

- H. R. Valentine, and J. R. E. Lutjeharms, 1993: Influence of the Agulhas Current on summer rainfall along the southeast coast of South Africa. J. Appl. Meteor., 32, 1282-1287, https://doi.org/ 10.1175/1520-0450(1993)032<1282:IOTACO > 2.0.CO;2.

Kirtman, B. P., and Coauthors, 2012: Impact of ocean model resolution on CCSM climate simulations. Climate Dyn., 39, 1303-1328, https://doi.org/10.1007/s00382-012-1500-3.

Kuwano-Yoshida, A., S. Minobe, and S. P. Xie, 2010: Precipitation response to the Gulf Stream in an atmospheric GCM. J. Climate, 23, 3676-3698, https://doi.org/10.1175/2010JCLI3261.1.

Le Bars, D., H. A. Dijkstra, and W. P. M. de Ruijter, 2013: Impact of the Indonesian Throughflow on Agulhas leakage. Ocean Sci., 9, 773-785, https://doi.org/10.5194/os-9-773-2013.

— J. V. Durgadoo, and H. A. Dijkstra, 2014: An observed 20 yr time-series of Agulhas leakage. Ocean Sci., 10, 601-609, https://doi.org/10.5194/os-10-601-2014.

Li, Z., J. C. McWilliams, K. Ide, and J. D. Farrara, 2015: Coastal ocean data assimilation using a multi-scale three-dimensional variational scheme. Ocean Dyn., 65, 1001-1015, https://doi.org/ 10.1007/s10236-015-0850-x.

Lilly, J. M., 2017: jLab: A data analysis package for Matlab, v.1.6.5. Accessed February 2017, http://www.jmlilly.net/jmlsoft.html.

Lindesay, J. A., 1988: South African rainfall, the Southern Oscillation and a Southern Hemisphere semi-annual cycle. Int. J. Climatol., 8, 17-30, https://doi.org/10.1002/joc.3370080103.

Loveday, B. R., J. V. Durgadoo, C. J. C. Reason, A. Biastoch, and P. Penven, 2014: Decoupling of the Agulhas leakage from the Agulhas Current. J. Phys. Oceanogr., 44, 1776-1797, https:// doi.org/10.1175/JPO-D-13-093.1.
- P. Penven, and C. J. C. Reason, 2015: Southern Annular Mode and westerly-wind-driven changes in Indian-Atlantic exchange mechanisms. Geophys. Res. Lett., 42, 4912-4921, https://doi.org/10.1002/2015GL064256.

Marshall, G. J., 2003: Trends in the southern annular mode from observations and reanalyses. J. Climate, 16, 4134-4143, https://doi. org/10.1175/1520-0442(2003)016<4134:TITSAM >2.0.CO;2.

Mason, S. J., 1995: Sea-surface temperature-South African rainfall associations, 1910-1989. Int. J. Climatol., 15, 119-135, https:// doi.org/10.1002/joc.3370150202.

McClean, J. L., and Coauthors, 2011: A prototype two-decade fully-coupled fine-resolution CCSM simulation. Ocean Modell., 39, 10-30, https://doi.org/10.1016/j.ocemod.2011.02.011.

Mey, R. D., N. D. Walker, and M. R. Jury, 1990: Surface heat fluxes and marine boundary layer modification in the Agulhas Retroflection region. J. Geophys. Res., 95, 15 997-16015, https:// doi.org/10.1029/JC095iC09p15997.

Minobe, S., A. Kuwano-Yoshida, N. Komori, S.-P. Xie, and R. J. Small, 2008: Influence of the Gulf Stream on the troposphere. Nature, 452, 206-209, https://doi.org/10.1038/nature06690.

Nkwinkwa Njouodo, A. S. N., S. Koseki, N. Keenlyside, and M. Rouault, 2018: Atmospheric signature of the Agulhas Current. Geophys. Res. Lett., 45, 5185-5193, https://doi.org/ 10.1029/2018GL077042.

Ou, H. W., and W. De Ruijter, 1986: Separation of an inertial boundary current from a curved coastline. J. Phys. Oceanogr., 16, 280-289, https://doi.org/10.1175/1520-0485(1986)016<0280: SOAIBC $>2.0 . \mathrm{CO} ; 2$.

Paris, C. B., J. Helgers, E. van Sebille, and A. Srinivasan, 2013: Connectivity Modeling System: A probabilistic modeling tool for the multi-scale tracking of biotic and abiotic variability in the ocean. Environ. Modell. Software, 42, 47-54, https://doi.org/ 10.1016/j.envsoft.2012.12.006.

Peeters, F. J. C., R. Acheson, G.-J. A. Brummer, W. P. M. de Ruijter, R. R. Schneider, G. M. Ganssen, E. Ufkes, and D. Kroon, 2004: Vigorous exchange between the Indian and Atlantic Oceans at the end of the past five glacial periods. Nature, 430, 661-665, https://doi.org/10.1038/nature02785.

Philippon, N., M. Rouault, Y. Richard, and A. Favre, 2012: The influence of ENSO on winter rainfall in South Africa. Int. J. Climatol., 32, 2333-2347, https://doi.org/10.1002/joc.3403.

Putrasahan, D., B. P. Kirtman, and L. M. Beal, 2016: Modulation of SST interannual variability in the Agulhas leakage region associated with ENSO. J. Climate, 29, 7089-7102, https://doi.org/ 10.1175/JCLI-D-15-0172.1.

Reason, C. J. C., 2001a: Evidence for the influence of the Agulhas Current on regional atmospheric circulation patterns. J. Climate, 14, 2769-2778, https://doi.org/10.1175/1520-0442(2001)014<2769: EFTIOT>2.0.CO;2.

_ 2001b: Subtropical Indian Ocean SST dipole events and southern African rainfall. Geophys. Res. Lett., 28, 2225-2227, https://doi.org/10.1029/2000GL012735.

— rainfall and SST anomalies in the Southwest Indian Ocean. Int. J. Climatol., 19, 1651-1673, https://doi.org/10.1002/(SICI) 1097-0088(199912)19:15<1651::AID-JOC439>3.0.CO;2-U.

— , and D. Jagadheesha, 2005: Relationships between South Atlantic SST variability and atmospheric circulation over the South African region during austral winter. J. Climate, 18, 3339-3355, https://doi.org/10.1175/JCLI3474.1.

_ and M. Rouault, 2005: Links between the Antarctic Oscillation and winter rainfall over western South Africa. Geophys. Res. Lett., 32, L07705, https://doi.org/10.1029/2005GL022419. 
,-- J. L. Melice, and D. Jagadheesha, 2002: Interannual winter rainfall variability in SW South Africa and large scale ocean-atmosphere interactions. Meteor. Atmos. Phys., 80, 1929, https://doi.org/10.1007/s007030200011.

Renault, L., J. C. McWilliams, and S. Masson, 2017a: Satellite observations of imprint of oceanic current on wind stress by air-sea coupling. Sci. Rep., 7, 17747, https://doi.org/10.1038/ s41598-017-17939-1.

_,- , and P. Penven, 2017b: Modulation of the Agulhas Current retroflection and leakage by oceanic current interaction with the atmosphere in coupled simulations. J. Phys. Oceanogr., 47, 2077-2100, https://doi.org/10.1175/JPO-D-16-0168.1.

Rhines, P. B., and W. R. Holland, 1979: A theoretical discussion of eddy-driven mean flows. Dyn. Atmos. Oceans, 3, 289-325, https://doi.org/10.1016/0377-0265(79)90015-0.

Richardson, P. L., 2007: Agulhas leakage into the Atlantic estimated with subsurface floats and surface drifters. Deep-Sea Res. I, 54, 1361-1389, https://doi.org/10.1016/j.dsr.2007.04.010.

Rouault, M., S. A. White, C. J. C. Reason, J. R. E. Lutjeharms, and I. Jobard, 2002: Ocean-atmosphere interaction in the Agulhas Current region and a South African extreme weather event. Wea. Forecasting, 17, 655-669, https://doi.org/10.1175/ 1520-0434(2002)017<0655:OAIITA > 2.0.CO;2.

_ , P. Penven, and B. Pohl, 2009: Warming in the Agulhas Current system since the 1980's. Geophys. Res. Lett., 36, L12602, https://doi.org/10.1029/2009GL037987.

- B. Pohl, and P. Penven, 2010: Coastal oceanic climate change and variability from 1982 to 2009 around South Africa. Afr. J. Mar. Sci., 32, 237-246, https://doi.org/10.2989/1814232X.2010.501563.

Singleton, A. T., and C. J. C. Reason, 2006: Numerical simulations of a severe rainfall event over the Eastern Cape coast of South Africa: Sensitivity to sea surface temperature and topography. Tellus, 58A, 335-367, https://doi.org/10.1111/ j.1600-0870.2006.00180.x.

_ and - 2007: Variability in the characteristics of cut-off low pressure systems over subtropical southern Africa. Int. J. Climatol., 27, 295-310, https://doi.org/10.1002/joc.1399.

Siqueira, L., and B. P. Kirtman, 2016: Atlantic near-term climate variability and the role of a resolved Gulf Stream. Geophys. Res. Lett., 43, 3964-3972, https://doi.org/10.1002/2016GL068694.

Small, R. J., and Coauthors, 2008: Air-sea interaction over ocean fronts and eddies. Dyn. Atmos. Oceans, 45, 274-319, https:// doi.org/10.1016/j.dynatmoce.2008.01.001.

_ - R. A. Tomas, and F. O. Bryan, 2014: Storm track response to ocean fronts in a global high-resolution climate model. Climate Dyn., 43, 805-828, https://doi.org/10.1007/s00382-013-1980-9.

Souza, J. M. A. C., C. de Boyer Montégut, C. Cabanes, and P. Klein, 2011: Estimation of the Agulhas ring impacts on meridional heat fluxes and transport using ARGO floats and satellite data. Geophys. Res. Lett., 38, L21602, https://doi.org/ 10.1029/2011GL049359.

— B. B. Chapron, and E. Autret, 2014: The surface thermal signature and air-sea coupling over the Agulhas rings propagating in the South Atlantic Ocean interior. Ocean Sci., 10, 633-644, https://doi.org/10.5194/os-10-633-2014.

Speich, S., J. R. E. Lutjeharms, P. Penven, and B. Blanke, 2006: Role of bathymetry in Agulhas Current configuration and behaviour. Geophys. Res. Lett., 33, L23611, https://doi.org/ 10.1029/2006GL027157.

Swart, N. C., and J. C. Fyfe, 2012: Observed and simulated changes in the Southern Hemisphere surface westerly wind-stress. Geophys. Res. Lett., 39, L16711, https://doi.org/10.1029/ 2012GL052810.

Thompson, D. W. J., and S. Solomon, 2002: Interpretation of recent Southern Hemisphere climate change. Science, 296, 895-899, https://doi.org/10.1126/science.1069270.

van Sebille, E., A. Biastoch, P. J. Van Leeuwen, and W. P. M. de Ruijter, 2009: A weaker Agulhas Current leads to more Agulhas leakage. Geophys. Res. Lett., 36, L03601, https://doi.org/ 10.1029/2008GL036614

— , P. J. van Leeuwen, A. Biastoch, and W. P. M. de Ruijter, 2010: Flux comparison of Eulerian and Lagrangian estimates of Agulhas leakage: A case study using a numerical model. Deep-Sea Res. I, 57, 319-327, https://doi.org/10.1016/j.dsr. 2009.12.006

—, M. H. England, J. D. Zika, and B. M. Sloyan, 2012: Tasman leakage in a fine-resolution ocean model. Geophys. Res. Lett., 39, L06601, https://doi.org/10.1029/2012GL051004.

_- J. Sprintall, F. U. Schwarzkopf, A. Sen Gupta, A. Santoso, M. H. England, A. Biastoch, and C. W. Böning, 2014: Pacificto-Indian Ocean connectivity: Tasman leakage, Indonesian Throughflow, and the role of ENSO. J. Geophys. Res. Oceans, 119, 1365-1382, https://doi.org/10.1002/2013JC009525. , and Coauthors, 2018: Lagrangian ocean analysis: Fundamentals and practices. Ocean Modell., 121, 49-75, https://doi.org/ 10.1016/j.ocemod.2017.11.008.

Walker, N. D., 1990: Links between South African summer rainfall and temperature variability of the Agulhas and Benguela Current systems. J. Geophys. Res., 95, 3297-3319, https://doi.org/ 10.1029/JC095iC03p03297.

— , and R. D. Mey, 1988: Ocean/atmosphere heat fluxes within the Agulhas Retroflection region. J. Geophys. Res., 93, 15 473-15 483, https://doi.org/10.1029/JC093iC12p15473.

Wang, Y., M. J. Olascoaga, and F. J. Beron-Vera, 2015: Coherent water transport across the South Atlantic. Geophys. Res. Lett., 42, 4072-4079, https://doi.org/10.1002/2015GL064089.

Weijer, W., and E. van Sebille, 2014: Impact of Agulhas leakage on the Atlantic Overturning Circulation in the CCSM4. J. Climate, 27, 101-110, https://doi.org/10.1175/JCLI-D-12-00714.1.

— W. P. M. de Ruijter, A. Sterl, and S. S. Drijfhout, 2002: Response of the Atlantic overturning circulation to South Atlantic sources of buoyancy. Global Planet. Change, 34, 293-311, https://doi.org/10.1016/S0921-8181(02)00121-2.

— , and Coauthors, 2012: The Southern Ocean and its climate in CCSM4. J. Climate, 25, 2652-2675, https://doi.org/10.1175/ JCLI-D-11-00302.1. 